\title{
Prediction of global solar radiation from sunrise duration using regression functions
}

\author{
Abd Al Karim Haj Ismail ${ }^{1,2, *}$ \\ ${ }^{1}$ Dept. of Mathematics and Sciences, \\ Ajman University, PO Box 346, United Arab Emirates \\ ${ }^{2}$ Nonlinear Dynamics Research Center (NDRC), \\ Ajman University, United Arab Emirates \\ *Corresponding author: a.hajismail@ajman.ac.ae
}

\begin{abstract}
The paper estimates the global solar radiation in Dubai and Abu Dhabi meteorological stations in the United Arab Emirates. Theoretical models based on Angstrom-Prescott have been applied to data of sunshine hours for the period from 2010 to 2019. The models are developed using 2010 - 2018 data and validated by comparing them to the 2019 data. Theoretical solar radiation estimates the maximum of global solar radiation to be in June for both stations, which is in good agreement with the actual data. The performance of the model is tested using statistical indicators such as the coefficient of determination $R^{2}$ and the Mean Root Square RMSE. The results show that the models were effective enough to describe the global solar radiation with overall $R^{2}$ of 0.8874 and $0.8706, R M S E$ of 0.0258 and $0.0241, M B E$ of 0.0412 and 0.0376 , and $M P E$ of 0.2371 and 0.2318 , for Abu Dhabi and Dubai meteorological stations, respectively.
\end{abstract}

Keywords: Angstrom-Prescott model; Clearness index; regression model; solar radiation; sunshine hours

\section{Introduction}

Nowadays, the seek for renewable energy sources is becoming very essential to overcome the large dependence on conventional fuel sources such as petrol and coal. The sun is the main source of free energy that is easily available in the atmosphere and the surface of Earth, providing about $99 \%$ of the energy needed for different processes on Earth. The study of solar radiation is used in several applications to predict the produced energy from power plants, climate modeling, and weather forecasting. Therefore, a solid understanding of solar radiation is very significant to estimate solar energy and develop solar energy projects and applications (Sumaryada et al., 2019). In addition, solar energy is considered an important source of renewable energy that is strongly encouraged and supported in many countries (Adomavicius, 2015; Kapitonov, 2019). In addition, it is one of the best options to get along with the increasing demand for clean energy to reduce pollution and fight against climate change sources (Yadav et al., 2014).

The distribution of the radiation at the top of the atmosphere is determined by some parameters. Characterizing these parameters leads to modeling the approach in order to obtain the appropriate distribution. Regression functions have become very powerful tools for estimating different meteorological and environmental indicators (Hafsa et al., 2017; Amiri et al., 2018). Therefore, available meteorological parameters such as sunrise duration, temperature, relative humidity, etc have been used to evaluate solar radiation at different locations (Koussa et al., 2009; Kumar et al., 2005). These studies rely on theoretical models for the estimation of global solar radiation such as the Angstrom-Prescott, which is a widely used model in the field of solar radiation (Prescott, 1940). In this paper, data on sunshine hours from two stations in the United Arab Emirates (Abu Dhabi and Dubai) are used to evaluate the global solar radiation using the Angstrom-Prescott model, and the measurement is compared to the actual data. 


\section{Materials and methods}

The horizontal daily solar radiation on the top of the atmosphere can be calculated using the following equation (Kumar et al., 2005):

$$
Q_{0}=\frac{24 I_{0}}{\pi}(\cos (\phi) \cdot \cos (\delta) \cdot \cos (w)+w \cdot \sin (\phi) \cdot \sin (\delta)),
$$

where $Q_{0}$ is the horizontal solar radiation at the top of the atmosphere, $I_{0}$ is the extraterrestrial radiation (given in Eq. 2), $\phi$ is the latitude of the station, $\delta$ is the declination angle (given in Eq. 3), and $w$ is the sunrise hour angle (given in Eq. 4).

$$
I_{0}=I_{s c}\left(1+0.033 \cos \left(\frac{360 d}{365}\right)\right)
$$

with $d$ is the day of the year $\left(d=1\right.$ for January $1^{s t}$ and 365 for December $\left.31^{s t}\right), I_{s c}=1370 \mathrm{~W} / \mathrm{m}^{2}$ is defined as the solar constant.

$$
\begin{gathered}
\delta=24.45 \sin \left(360 \frac{284+d}{365}\right), \\
w=\cos ^{-1}(-\tan (\phi) \tan (\delta)),
\end{gathered}
$$

The clearness index $K$ is an important parameter that is generally used to describe the effect of atmospheric attenuation on extraterrestrial radiation. It is defined as the ratio between the global solar radiation at the surface $(Q)$ and the extraterrestrial solar radiation $\left(Q_{0}\right)$. In order to estimate the global solar radiation from sunshine hours, many regression models based on Angstrom and Prescott can be used. We apply three types of regression models in this work, the Angstrom-Prescott Linear model (Prescott, 1940) (Eq. 5), Logarithmic (Ampratwum et al., 1999) (Eq. 6) and an Exponent function (Bakirci, 2009) (Eq. 7), as follows:

$$
\begin{gathered}
K=\frac{Q}{Q_{0}}=a+b\left(\frac{n}{N}\right), \\
K=\frac{Q}{Q_{0}}=a+b \log \left(\frac{n}{N}\right), \\
K=\frac{Q}{Q_{0}}=a \exp \left(\frac{n}{N}\right)^{b},
\end{gathered}
$$

with $Q$ is the global solar radiation at the surface, $n$ is the monthly average observed sunshine duration, $N$ is monthly maximum possible sunshine duration, and $a, b$ are the regression constants.

The sunrise, sunset, and solar radiation data are provided by the National Center of Meteorology (NCM, 2020) for two stations, Abu Dhabi and Dubai, in the United Arab Emirates. Ten years of data was provided for the period between the beginning of 2010 and the end of 2019. An overview of the data is presented in Table 1 and Table 2. Distributions of the solar radiation and sunrise hours, for Abu Dhabi and Dubai meteorological stations, are shown in Figure 1. The summer season in the UAE starts in May, and that results in a high solar radiation in May, June, and July. A maximum average solar radiation is measured in June in both stations. The sunshine duration factor varies between 10.5 and 13.5 hours per day for both stations with a maximum sunshine time around May to July, which could also explain the higher values of the solar radiation in these months. On the other hand, the solar radiation has lower values in the rest of the year, reaching its minimum in December and January.

The coefficients $a$ and $b$ represent the properties of the atmosphere. In (Revfeim et al., 1993), the coefficients are interpreted as; $a$ to present the transmissivity of an overcast sky, and the sum of the constants $(a+b)$ as the transmissivity of the atmosphere in clear sky conditions $(n / N=1)$. An overview of the obtained coefficients from regression models is presented in Table 3. 
Table 1. Overview of average monthly solar radiation, clearness index, average sunshine, and maximum sunshine duration in Abu Dhabi station.

\begin{tabular}{|c|c|c|c|c|}
\hline & \multicolumn{4}{|c|}{$\begin{array}{c}\text { ABU DHABI } \\
\text { Latitude } 24^{\circ} 28^{\prime} 38^{\prime \prime} \mathrm{N} \\
\text { Longitude: } 54^{\circ} 19^{\prime} 40^{\prime \prime} \mathrm{E}\end{array}$} \\
\hline & $Q\left(\mathrm{Wh} / \mathrm{m}^{2}\right)$ & $K$ & $n(\mathrm{~h})$ & $N(\mathrm{~h})$ \\
\hline Jan. & 4473.00 & 0.674 & 10.81 & 11.30 \\
\hline Feb. & 5164.69 & 0.681 & 11.33 & 11.97 \\
\hline March & 6054.06 & 0.664 & 12.01 & 12.70 \\
\hline April & 6719.87 & 0.682 & 12.41 & 13.3 \\
\hline May & 7511.42 & 0.666 & 13.33 & 13.65 \\
\hline June & 7704.57 & 0.667 & 13.64 & 13.68 \\
\hline July & 7166.13 & 0.685 & 13.50 & 13.52 \\
\hline August & 7064.68 & 0.711 & 12.98 & 13.00 \\
\hline Sept. & 6721.37 & 0.726 & 12.30 & 12.30 \\
\hline Oct. & 5831.10 & 0.713 & 11.58 & 11.60 \\
\hline Nov. & 4794.67 & 0.703 & 10.96 & 10.97 \\
\hline Dec. & 4338.52 & 0.689 & 10.65 & 10.63 \\
\hline
\end{tabular}

Table 2. Overview of average monthly solar radiation, clearness index, average sunshine, and maximum sunshine duration in Dubai station.

\begin{tabular}{|c|c|c|c|c|}
\hline & \multicolumn{4}{|c|}{$\begin{array}{c}\text { Latitude: } 25^{\circ} 15^{\prime} 10^{\prime \prime} \mathrm{N} \\
\text { Longitude: } 55^{\circ} 21^{\prime} 52^{\prime \prime} \mathrm{E}\end{array}$} \\
\hline & $Q\left(\mathrm{Wh} / \mathrm{m}^{2}\right)$ & $K$ & $n(\mathrm{~h})$ & $N(\mathrm{~h})$ \\
\hline Jan. & 4246.55 & 0.682 & 10.76 & 11.30 \\
\hline Feb. & 4881.72 & 0.672 & 11.30 & 11.95 \\
\hline March & 5761.28 & 0.663 & 12.01 & 12.72 \\
\hline April & 6575.18 & 0.661 & 12.42 & 13.37 \\
\hline May & 7289.06 & 0.683 & 13.38 & 13.72 \\
\hline June & 7555.71 & 0.679 & 13.70 & 13.73 \\
\hline July & 7022.32 & 0.692 & 13.55 & 13.58 \\
\hline August & 6701.07 & 0.711 & 13.01 & 13.03 \\
\hline Sept. & 6246.99 & 0.721 & 12.30 & 12.32 \\
\hline Oct. & 5527.74 & 0.717 & 11.57 & 11.58 \\
\hline Nov. & 4574.4 & 0.705 & 10.92 & 10.93 \\
\hline Dec. & 4256.36 & 0.709 & 10.59 & 10.58 \\
\hline
\end{tabular}

Table 3. The coefficients of the applied models for Abu Dhabi and Dubai stations.

\begin{tabular}{l|l|ll}
\hline \multicolumn{5}{|c}{$a \times 10^{2}$} & $b \times 10^{2}$ \\
\hline Abu & Lin. & $28.44 \pm 0.23$ & $42.33 \pm 0.38$ \\
Dhabi & Log. & $70.39 \pm 0.19$ & $10.59 \pm 0.13$ \\
& Exp. & $-199.8 \pm 3.68$ & $11.74 \pm 0.27$ \\
\hline \multirow{3}{*}{ Dubai } & Lin. & $-17.40 \pm 0.15$ & $88.82 \pm 0.91$ \\
& Log. & $70.14 \pm 0.81$ & $93.20 \pm 0.98$ \\
& Exp. & $-199.2 \pm 4.21$ & $24.39 \pm 0.57$ \\
\hline
\end{tabular}




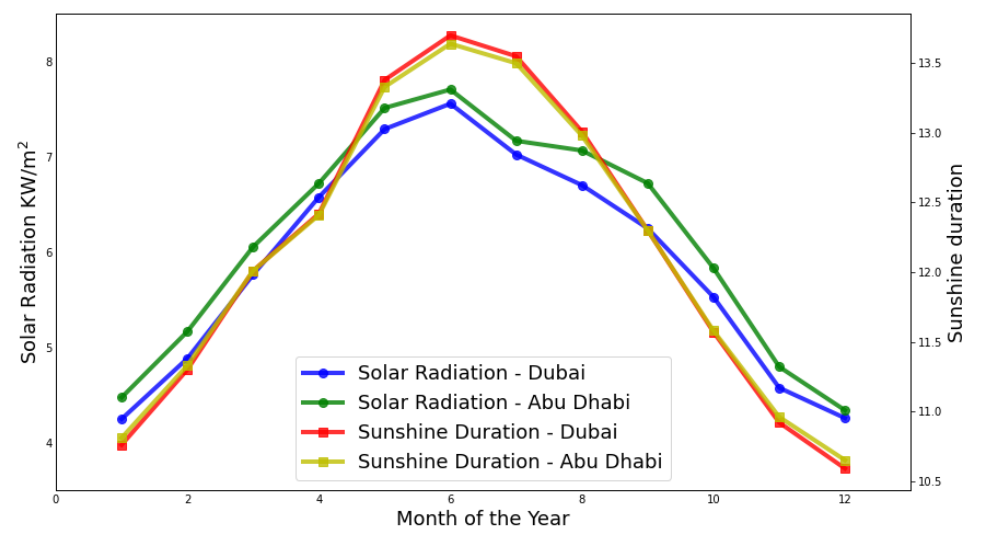

Fig. 1. The mean values of the measured solar radiation (left y-axis; circles) and sunrise duration (right y-axis; squares) for Abu Dhabi and Dubai stations.

The models were developed using nine years of data (2010 - 2018) and validated by comparing to 2019 data. Furthermore, the performance of the procedure is evaluated using a fundamental error method that is commonly used in solar energy researches (Ma et al., 1984). Statistical indicators were optimized using ROOT (Rene et al., 1997), namely coefficient of determination $R^{2}$, root mean square error $R M S E$, mean bias error $M B E$, and mean percentage error $M P E$ (defined in Equations 8, 9, 10 and 11 , respectively).

$$
\begin{gathered}
R^{2}=1-\frac{\sum_{i=1}^{M}\left(Q_{i m}-Q_{i e}\right)^{2}}{\sum_{i=1}^{M}\left(Q_{i m}-Q_{a v g, m}\right)^{2}} \\
R M S E=\left(\frac{\sum_{i=1}^{M}\left(Q_{i e}-Q_{i m}\right)^{2}}{M}\right)^{\frac{1}{2}} \\
M B E=\frac{1}{M} \sum_{i=1}^{M}\left(Q_{i e}-Q_{i m}\right) \\
M P E=\frac{1}{M} \sum_{i=1}^{M} \frac{Q_{i m}-Q_{i e}}{K_{i m}} \times 100
\end{gathered}
$$

where $Q_{i e}, Q_{i m}$, and $Q_{a v g, m}$ are the $i^{\text {th }}$ estimated, measured, and average measured solar radiation values, respectively, and $M$ represents the total number of measurements. $R M S E$ presents the difference between estimated and measured values. $M B E$ and $M P E$ evaluate the precision of the estimated values.

\section{Results}

The meteorological data of Abu Dhabi and Dubai stations are processed to estimate the global solar radiation at the surface. Figure 2 and 3 show a comparison between the measured solar radiation values and the estimated values by the linear, logarithmic, and exponent models, in Abu Dhabi and Dubai stations, respectively. The first nine years of data (2010 - 2018) are used for the development of the models and 2019 data is used for validation and comparison purposes. The prediction from regression models shows a good agreement across the year. The measured solar radiation varies between $(4338.52$ $\mathrm{Wh} / \mathrm{m}^{2}$ in December $-7166.13 \mathrm{Wh} / \mathrm{m}^{2}$ in June) and $\left(4246.55 \mathrm{Wh} / \mathrm{m}^{2}\right.$ in January $-7555.71 \mathrm{Wh} / \mathrm{m}^{2}$ in June) for Abu Dhabi and Dubai stations, respectively. The peaks of the predicted solar radiation from the three regression functions show significant agreement with the measured solar radiation values. All predicted maximum values are also obtained in June (Abu Dhabi: $8021.1 \mathrm{Wh} / \mathrm{m}^{2}, 7824.73 \mathrm{Wh} / \mathrm{m}^{2}$, 


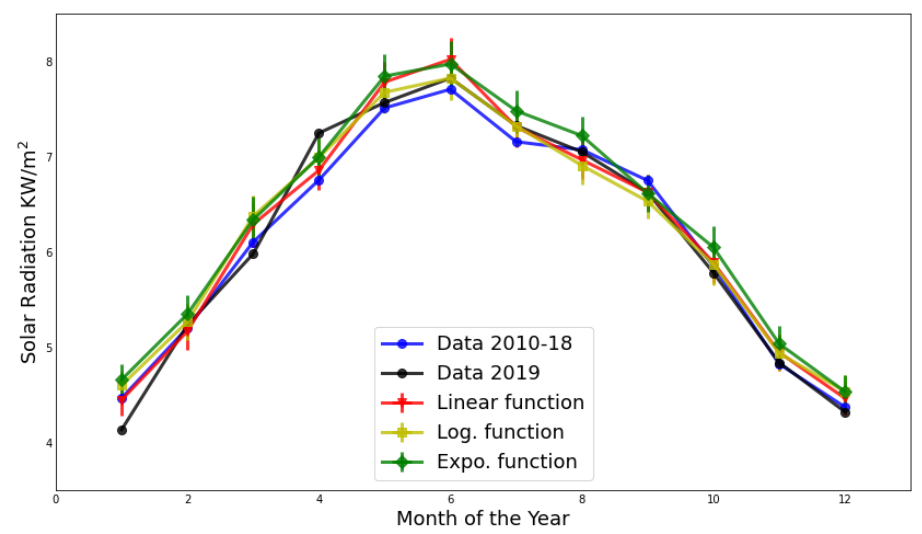

Fig. 2. The measured global solar radiation compared to the prediction from regression models for Abu Dhabi station. The vertical lines correspond to the error implied by the retrieval uncertainty of the modeled coefficients.

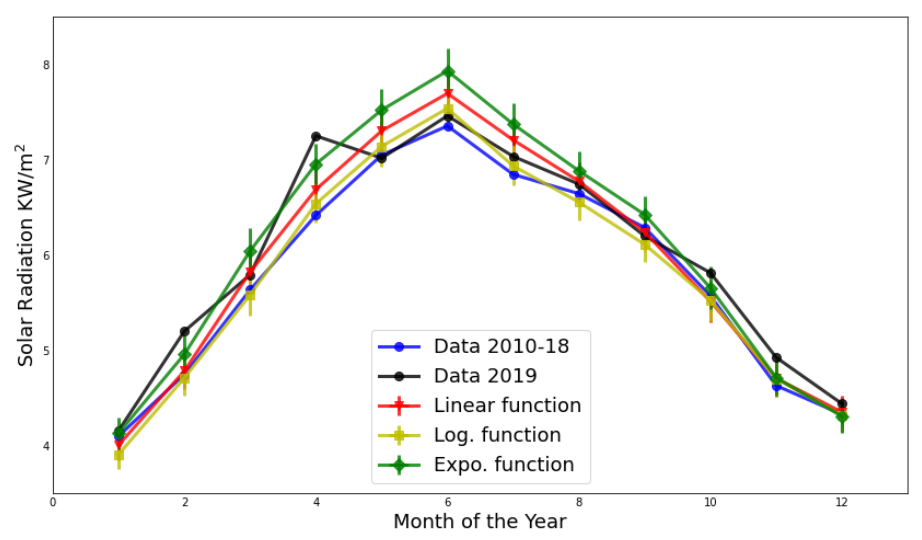

Fig. 3. The measured global solar radiation compared to the prediction from regression models for Dubai station. The vertical lines correspond to the error implied by the retrieval uncertainty of the modeled coefficients.

$7972.59 \mathrm{Wh} / \mathrm{m}^{2}$ ) and (Dubai: $7694.9 \mathrm{Wh} / \mathrm{m}^{2}, 7538 \mathrm{Wh} / \mathrm{m}^{2}, 7931,92 \mathrm{Wh} / \mathrm{m}^{2}$ ) for the linear, logarithmic, and exponent regression functions, respectively. Results of the theoretical and measured values are summarized in Table 4 and Table 5.

Table 6 shows an overview of the derived statistical parameters. The obtained values of the coefficient of determination $R^{2}$ (about 0.87 in average), and $R M S E$ (about 0.026 in average) give us good confidence in the performance of the models.

Discrimination in the models performance on seasonal basis can also be observed. This discrimination is larger in Dubai station than Abu Dhabi station, and it is more pronounced in the summer period (April through September). However, this discrimination is within the presented model uncertainties. Furthermore, other meteorological parameters such as humidity, pressure, temperature etc., can play an important role in the observed seasonal variation dependence. Detailed seasonal variation analysis is not presented in this paper and will be discussed in future work. 
Table 4. A comparison of measured solar radiation values and obtained values from regression models for Abu Dhabi station.

\begin{tabular}{c|cccc}
\hline & \multicolumn{4}{c}{ ABU DHABI } \\
\cline { 2 - 5 } Q & Meas. & Lin. & Log. & Exp. \\
\hline Jan. & 4473.00 & 4447.78 & 4599.76 & 4659.49 \\
Feb. & 5164.69 & 5166.98 & 5267.08 & 5347.47 \\
Mar. & 6054.06 & 6290.25 & 6374.13 & 6337.66 \\
Apr. & 6719.87 & 6855.87 & 6990.86 & 6996.78 \\
May & 7511.42 & 7782.08 & 7674.94 & 7845.24 \\
June & 7704.57 & 8021.10 & 7824.73 & 7972.59 \\
July & 7166.13 & 7311.62 & 7322.08 & 7481.09 \\
Aug. & 7064.68 & 6966.23 & 6906.62 & 7219.60 \\
Sept. & 6721.37 & 6625.12 & 6531.61 & 6614.01 \\
Oct. & 5831.10 & 5889.17 & 5869.54 & 6048.64 \\
Nov. & 4794.67 & 4945.33 & 4936.46 & 5036.04 \\
Dec. & 4338.52 & 4463.70 & 4534.23 & 4534.86 \\
\hline
\end{tabular}

Table 5. A comparison of measured solar radiation values and obtained values from regression models for Dubai station.

\begin{tabular}{l|cccc}
\hline & \multicolumn{4}{c}{ DUBAI } \\
\cline { 2 - 5 } Q & Meas. & Lin. & Log. & Exp. \\
\hline Jan. & 4246.55 & 4006.16 & 3907.15 & 4130.69 \\
Feb. & 4881.72 & 4782.28 & 4709.63 & 4957.35 \\
Mar. & 5761.28 & 5821.26 & 5581.42 & 6041.98 \\
Apr. & 6575.18 & 6686.61 & 6537.40 & 6954.19 \\
May & 7289.06 & 7301.91 & 7138.62 & 7520.69 \\
June & 7555.71 & 7694.90 & 7538.00 & 7931.92 \\
July & 7022.32 & 7205.87 & 6933.92 & 7372.30 \\
Aug. & 6701.07 & 6773.57 & 6553.97 & 6881.96 \\
Sept. & 6246.99 & 6240.07 & 6110.10 & 6422.89 \\
Oct. & 5527.74 & 5512.28 & 5525.39 & 5653.36 \\
Nov. & 4574.40 & 4705.37 & 4700.82 & 4711.20 \\
Dec. & 4256.36 & 4349.35 & 4312.13 & 4306.73 \\
\hline
\end{tabular}

Table 6. Coefficients of statistical performance of the regression models for Abu Dhabi and Dubai stations.

\begin{tabular}{lllll}
\hline & $R^{2}$ & RMSE & MBE & MPE \\
\hline \multicolumn{5}{c}{ Abu Dhabi } \\
\hline Lin. & 0.8912 & 0.0261 & 0.0413 & 0.2132 \\
Log. & 0.8865 & 0.0251 & 0.0446 & 0.2261 \\
Exp. & 0.8846 & 0.0262 & 0.0377 & 0.2719 \\
\hline \multicolumn{5}{c}{ Dubai } \\
\hline Lin. & 0.8755 & 0.0245 & 0.0386 & 0.2417 \\
Log. & 0.8651 & 0.0241 & 0.0350 & 0.2582 \\
Exp. & 0.8713 & 0.0238 & 0.0391 & 0.1954 \\
\hline
\end{tabular}




\section{Discussion}

The meteorological data of Abu Dhabi and Dubai stations are used to estimate the global solar radiation using the sunrise duration parameter. Linear, Logarithmic, and exponent regression models are used to estimate the global solar radiation at the surface. The application of these methods to the global solar radiation of Abu Dhabi and Dubai stations showed a general agreement between the measured data and the estimated values from the three used models, within uncertainties of the coefficients of the models. However, the logarithmic model shows a better description of the data than the linear and exponential functions. The proposed methods predicted the maximum global solar radiation in June in both stations, with an average $R^{2}$ of 0.89 and 0.87 , average $R M S E$ of 0.026 and 0.024 , average $M B E$ of 0.041 and 0.038 , and average $M P E$ of 0.24 and 0.23 , for Abu Dhabi and Dubai stations, respectively. Moreover, other meteorological parameters such as average temperature, humidity, and pressure can also be used to extend the study. Moreover, other regression models based on Angstrom and Prescott such as Quadratic and cubic functions can be also tested in the future. In addition, more mathematical approaches can be implemented such as fuzzy logic and aggregation functions, which are becoming good mathematical candidates to convert many input values into a representative output value (Ahmad et al., 2016; Jwaid et al., 2021; Haj Ismail et al., 2021; Ismail et al., 2021).

\section{ACKNOWLEDGEMENTS}

The author acknowledges the National Centre of Meteorology in the United Arab Emirates for supporting the research and providing the data for the analysis. The author also acknowledges Ajman University for funding and supporting the research, Internal Research Grant No:[DGSR Ref. 2021-IRG-HBS-12].

\section{References}

Adomavicius, V., \& Kaminickas, M. (2015). Analysis of PV power future development possibilities. In Kuwait Journal of Science. 60, 233 - 248.

Ahmad, A., Muhammad, Y. Q., Qadri, N. N., \& Ahmad, J., (2016). Fuzzy logic based adaptive MPSoC for balanced energy and throughput. In Kuwait Journal of Science. 43, 91 - 100.

Amiri, M. A., Conoscenti C.,\& Mesgari, M. S. (2018). Improving the accuracy of rainfall prediction using a regionalization approach and neural networks. In Kuwait Journal of Science. 45, 66 - 75.

Ampratwum, D. B., \& Dorvlo, A. (2020). Estimation of solar radiation from the number of sunshine hours. In Applied Energy, 63, 161 - 167.

Bakirci, K. (2009). Correlations for estimation of daily global solar radiation with hours of bright sunshine in Turkey. In Energy. 34, 485 - 501.

Hafsa, B., Sheikh S. A., Rabail U.,\& Muhammad, N. (2017). Modeling some plant species distribution against environmental gradients using multivariate regression models. In Kuwait Journal of Science. 44, 119 - 128.

Haj Ismail, A., Dawi, E.A., Jwaid, T., Mahmoud, S.T, \& AbdelKader, A., (2021). Simulation of the evolution of the Covid-19 pandemic in the United Arab Emirates using the sir epidemical model. In Arab Journal of Basic and Applied Sciences. 28, 128 - 134.

Ismail, A.H., Waseem, H.M., Ishtiaq, M., Jamal, S.S., \& Khan, M., (2021). Quantum Spin Half Algebra and Generalized Megrelishvili Protocol for Confidentiality of Digital Images. In International Journal Theoretical Physics. 60, 1720 - 1741.

Jwaid, T., De Meyer, H., Haj Ismail, A., \& De Baets, B., (2021). Curved splicing of copulas. In Information Sciences. 556, 95 - 110.

Kapitonov, I. A. (2019). Simulation of the extra-terrestrial and terrestrial performance of GaAs/Ge dualjunction solar cells. In Kuwait Journal of Science. 46, 58 - 65. 
Koussa, M., Malek, A., \& Hernández-Javier, A. L., (2009). Statistical comparison of monthly mean hourly and daily diffuse and global solar irradiation models and a Simulink program development for various Algerian climates. In Energy Conversion and Management. 50, 1227 - 1235.

Kumar, R., \& Umanand, L. (2009). Estimation of global radiation using clearness index model for sizing photovoltaic system. In Renewable Energy. 30, 2221 - 2233.

Ma, C. C. Y., \& Iqbal, M., (1984). Statistical comparison of solar radiation correlations Monthly average global and diffuse radiation on horizontal surfaces. In Solar Energy. 33, 143 - 148.

Kucharski, N.C.M. (2020). The National Center of Meteorology. UAE. In www.ncm.ae.

Prescott, J. (1940). Evaporation from a Water Surface in Relation to Solar Radiation. In Transactions of the Royal Society of South Australia. 64, 114 - 118.

Rene, B., \& Fons, R., (1997). ROOT - An object-oriented data analysis framework. In Nuclear Instruments and Methods in Physics Research Section A: Accelerators, Spectrometers, Detectors and Associated Equipment. 389, 81 - 86.

Revfeim, K. J. A. (1993). An interpretation of the coefficients of the Angstrom Equation. In Solar Energy. 31, 415 - 416.

Sumaryada, T., Sofyan, A., Syafutra, H.,\& Muhammad, N. (2019). Legal support for integration of renewable energy sources in the energy law of the countries from the inter-national legal position. In Kuwait Journal of Science. 46, 68 - 75.

Yadav, A. M., \& Chandel, S. S. (2014). Solar radiation prediction using Artificial Neural Network techniques: A review. In Renewable and Sustainable Energy Reviews. 33, 772 - 781.

$\begin{array}{ll}\text { Submitted: } & 07 / 07 / 2021 \\ \text { Revised: } & 29 / 08 / 2021 \\ \text { Accepted: } & 30 / 08 / 2021 \\ \text { DOI: } & 10.48129 / \text { kjs. } 15051\end{array}$

